\title{
Dietary vitamin D3 affects digestive system ontogenesis and ossification in European sea bass (Dicentrachus labrax, Linnaeus, 1758)
}

\author{
Maria J. Darias ${ }^{\mathbf{a},{ }^{*}, \text { David Mazurais }}{ }^{\mathbf{a}}$, Giorgos Koumoundouros ${ }^{\mathbf{b}}$, Nomiki Glynatsi ${ }^{\mathbf{b}}$, Stavroula \\ Christodoulopoulou $^{\mathbf{b}}$, Christine Huelvan ${ }^{\mathbf{a}}$, Elisabeth Desbruyeres ${ }^{\mathbf{a}}$, Marie M. Le Gall ${ }^{\mathbf{a}}$, Patrick \\ Quazuguel $^{\mathbf{a}}$, Chantal L. Cahu ${ }^{\mathrm{a}}$ and Jose L. Zambonino-Infante ${ }^{\mathrm{a}}$
}

\author{
a Ifremer Marine Fish Nutrition Team, Nutrition Aquaculture and Genomics Research Unit, UMR 1067, Ifremer, \\ Technopole Brest-Iroise, BP 70, 29280 Plouzané, France \\ ${ }^{\mathrm{b}}$ University of Patras, Biology Department, 26500 Patras, Rio, Greece \\ *: Corresponding author : Maria J. Darias, Tel.: + 34977745 427; fax: + 34977744 138, email address : \\ Maria.Darias@irta.cat
}

\begin{abstract}
:
The influence of dietary vitamin $\mathrm{D}_{3}\left(\mathrm{VD}_{3}\right)$ on survival, growth and morphogenesis during the larval development of European sea bass (Dicentrarchus labrax) was evaluated until 45 days post hatching. Diets contained $4 \%$ of the standard vitamin mix (VM) recommended by the National Research Council (NRC) and incorporated $0,19.2,38.4$, or $140 \mathrm{IU}$ of $\mathrm{VD}_{3}$ per gram of diet to give VD-0, VD-1, VD-2 and VD-3 dietary treatments, respectively. The present study revealed for the first time an impact of dietary $\mathrm{VD}_{3}$ on the sea bass digestive system ontogenesis that consequently conditioned the ossification process and morphogenesis. All dietary $\mathrm{VD}_{3}$ levels were in the "adequate range" based on larval survival. Nevertheless, growth, intestinal maturation and ossification at the end of the larval stage were harmed by the minimum dose of $\mathrm{VD}_{3}$ tested and resulted in the appearance of malformations. VD-2 and VD-3 groups showed satisfactory growth and ossification levels at the end of the larval period. However, results of enzymatic activity and expression of genes involved in the $\mathrm{VD}_{3}$ pathway (bone morphogenetic protein 4 , osteocalcin, vitamin $\mathrm{D}$ receptors and transient receptor potential cation channel-subfamily $\mathrm{V}$, member 6-) gave evidence of complications during the ossification process as revealed by the high percentage of deformed larvae. $\mathrm{A} \mathrm{VD}_{3}$ level of $19.2 \mathrm{lU} / \mathrm{g}$ diet appeared necessary to obtain harmonious larval morphogenesis.
\end{abstract}

Keywords: Fish larvae; Ossification; Malformations; Vitamin D; Digestive system; Gene expression 


\section{Introduction}

18 The understanding of the nutritional influence on fish larval skeletogenesis is relevant, not only to deepen

19 the knowledge of bone physiology, but to aid in resolving one of the most important bottlenecks in reared

20 fish larvae, the skeletal malformations, that cause a severe economic impact for the aquaculture industry.

21 Efforts have been made to study the different factors influencing fish larval morphogenesis and to

22 understand the mechanisms inducing the development of deformities (Koumoundouros et al., 2002;

23 Sfakianakis et al., 2006; Georgakopoulou et al., 2007). Among the different causative factors, larval

24 nutrition has been suggested as of key role in skeletogenesis (Cahu et al., 2003; Gisbert 2007; Lall \&

25 Lewis-McCrea 2007). However, there are still improvements to be made on, since skeletal disorders

26 continue affecting the hatcheries' production.

27 The known influence of vitamins on the appearance of larval malformations (Dedi et al., 1997; Takeuchi

28 et al., 1998; Villeneuve et al., 2005; Fernández et al., 2008, 2009) has encouraged researchers to

29 understand the molecular mechanisms underlying the skeletogenesis process and to determine more

30 accurately the dietary vitamin levels inducing adequate larval morphogenesis (Villeneuve et al., 2006;

31 Mazurais et al., 2008). Mazurais and co-workers stated that fish larvae need higher dietary vitamin mix

32 than juveniles and concluded that the level of vitamin mix adapted by the NRC for the fish larval period

33 gave the best larval growth, survival and morphogenesis (NRC 1993; Mazurais et al., 2008). However,

34 since the percentage of malformations remained still too elevated, it seems now appropriate to investigate

35 the effects of each vitamin separately on larval ontogenesis.

36 Vitamin D is a fat-soluble pro-hormone that is crucial for maintaining calcium and phosphate homeostasis

37 and protecting skeletal integrity (De Luca 2004). This hormone functions through the vitamin D receptor

38 (VDR) inducing the expression of various calcium binding and transport proteins in the intestine to

39 stimulate active calcium uptake, thus preserving normocalcemia and, indirectly, maintaining bone

40 mineralization. Besides, vitamin D also acts directly on osteoblasts, the resident bone-forming cells of the

41 skeleton, to inhibit proliferation, modulate differentiation and regulate mineralization of the extracellular

42 matrix (Sutton et al., 2005).

43 Few studies exist on the role of vitamin D on the development of skeletal deformities in fish, among them

44 only one was performed in juveniles (Haga et al., 2004) while the information on the vitamin D

45 requirements of fish during the larval period was still missing. Continuing with the characterization of the 

by Mazurais et al. (2008), the present study aimed to test whether $\mathrm{VD}_{3}$ affects the ontogeny of this species by studying its influence on the molecular pathways involved in morphogenesis, with special attention to the ossification process.

\section{Material and methods}

\subsection{Larval rearing and dietary treatment}

54 Three-day old European sea bass (Dicentrarchus labrax) larvae were obtained from the Ecloserie Marine de Gravelines (Gravelines, France). The fish were acclimated and divided into fifteen 35-litre cylindroconical fibreglass tanks (2100 larvae/tank) at an initial density of 60 larvae/l. Tanks were supplied with through-flowing seawater, which had been previously filtered through a sand filter, then passed successively through a tungsten heater and a degassing column packed with plastic rings. Throughout the experiment, salinity was 35\%, the oxygen level was maintained above $6 \mathrm{mg} / \mathrm{l}$ by setting the water replacement in the tank at up to $30 \%$ per hour (flow rate, $0.18 \mathrm{l} / \mathrm{min}$ ) and the photoperiod was

$6124 \mathrm{~h}$ light $\left(9 \mathrm{~W} / \mathrm{m}^{2}\right.$ maximum intensity at the water surface). All procedures concerning the animals and their handling were conducted in compliance with the Guide for the Care and Use of Laboratory Animals (NRC 1996). The study was performed under the licence no. 29.021 by the French Department of Veterinary Services (Direction Départementale des Services Vétérinaires) to conduct experimental protocols and samplings on fish. To provide a wider range of dose levels and have more flexibility in the formula, the concentration of the standard vitamin mix (VM) was doubled (NRC 1993). Consequently, $1 \%$ concentrated-vitamin mix used in this experiment corresponds to $2 \%$ standard VM. Microdiets (200$400 \mu \mathrm{m}$ of pellet size) were prepared as previously described (Cahu et al., 2003). Six experimental groups (four replicates per group) of sea bass larvae were reared at $20^{\circ} \mathrm{C}$ and fed, from day 9 until day 45 post hatching (dph), on microparticulate diets incorporating 0 (VD-0), 19.2 (VD-1), 38.4 (VD-2), and 140 (VD-3) IU of vitamin $\mathrm{D}_{3}\left(\mathrm{VD}_{3}\right)$ per gram of the diet. The source of vitamin $\mathrm{D}_{3}$ was ROVIMIX ${ }^{\circledR} \mathrm{D}_{3}-500$. The composition of the diet is described in Table 1. VD-1 corresponds to the control diet (Mazurais et al., 2008). Biochemical analysis once diet was elaborated indicated the following $\mathrm{VD}_{3}$ (cholecalcipherol) content, 11.2 (VD-0), 27.6 (VD-1), 42 (VD-2) and 120 (VD-3) IU VD 3 per gram of diet. Larvae were fed in excess (24/24 h) using automatic belt feeders in order to facilitate the encounter opportunity of the diet. 
76 Food intake was checked by direct observation of the larval digestive tract under a binocular microscope

$77 \quad 1 \mathrm{~h}$ after feed distribution started.

80 Thirty larvae were collected from each tank for weight measurement (formalin preserved) every week, and at the end of the experiment. Survival was evaluated by counting the individuals in each tank at the end of the experiment. Forty larvae per tank of $45 \mathrm{dph}$ were sampled to determine the ossification level and 48-65 larvae to examine the incidence of skeletal malformations. For each treatment, $200 \mathrm{mg}$ (wet body weight) larvae were collected at 11, 22 and $45 \mathrm{dph}$, and total RNA was immediately extracted to measure the expression of several genes involved in larval development. Prior to daily food distribution, larvae were sampled from each tank at $25 \mathrm{dph}(\mathrm{n}=100)$ and $45 \mathrm{dph}(\mathrm{n}=30)$, immediately frozen, and stored at $-20^{\circ} \mathrm{C}$ for enzyme assays.

\subsection{Analytical methods}

90 Larvae were double-stained with Alcian blue and Alizarin red S to demonstrate cartilage and bone,

91 respectively. Larvae from the different experimental groups were stained simultaneously in order to 92 prevent any technical variability. Image analysis of the ossified larval surface was carried out as described 93 in Mazurais et al., (2008).

94 For enzymatic assays, larvae were dissected as described by Cahu \& Zambonino-Infante (1994) in order to separate pancreatic and intestinal segments. The dissected segments were homogenized in five volumes $(\mathrm{v} / \mathrm{w})$ of cold distilled water $\left(4^{\circ} \mathrm{C}\right)$. Trypsin and amylase were assayed according to Holm et al., (1988) and Métais \& Bieth (1968), respectively. Brush border membranes (bbm) were purified from the intestinal segment homogenate according to a method developed for intestinal scraping (Crane et al., 1979; Zambonino-Infante et al., 1997). Enzymes of the bbm, alkaline phosphatase (AP) and

100 aminopeptidase N (AN) were assayed according to Maroux et al., (1973) and Bessey et al., (1946),

101 respectively. Assay of a cytosolic enzyme, leucine-alanine peptidase (LeuAla), was performed using the

102 method of Nicholson and Kim (Nicholson and Kim, 1975). Protein was determined by the procedure of 103 Bradford (1976). 
105 Data on pancreatic enzymes (amylase and trypsin, mU/segment) were expressed as a ratio of activity in

106 intestinal segment (I) related to that in both pancreatic (P) and intestinal segment (total amylase or trypsin

107 content). This ratio reflects the secretion of pancreatic enzymes (Zambonino-Infante 1996). Data on

108 intestinal enzymes were expressed as a ratio of AP and AN activity (mU/segment) in bbm related to the

109 activity of the cytosolic enzyme LeuAla peptidase (U/segment). This ratio reflects the maturation of the

110 intestine.

111 The following genes have been chosen as markers and their expression was analysed during the larval

112 period: vitamin D receptors (VDR $\alpha$ and $\operatorname{VDR} \beta$ ) (St-Arnaud 2008), which mediate the action of $\mathrm{VD}_{3}$,

113 bone morphogenetic protein 4 (BMP-4) (Mazurais et al., 2008) and osteocalcin (Lian \& Stein 1995),

114 which are implied in osteoblast differentiation and mineralization, respectively, and the transient receptor

115 potential cation channel-subfamily V, member 6- (TRPV6) (Nijenhuis et al., 2005), involved in the

116 intestinal absorption of calcium, necessary for bone mineralization. Total RNA was extracted using

117 TRIzol and reverse-transcribed in duplicate (iScript cDNA Synthesis Kit, Bio-Rad Laboratories,

118 Hercules, CA) and then pooled. Quantitative PCR analyses for each gene were performed in triplicate in a

119 total volume of $15 \mu 1$ containing $5 \mu 1 \mathrm{cDNA}$ (dilution, $10^{-2}$ ), $0.5 \mu 1$ primers $(10 \mu \mathrm{mol} / \mathrm{l}), 7.5 \mu 1$ iQ SYBR

120 Green supermix 2X (Bio-Rad Laboratories), and $2 \mu \mathrm{l}$ sterile water. For each target gene specific

121 complementary primers, designed from previously cloned sequences, are listed in Table 2. The

122 housekeeping gene EF1 was chosen as a reference since it did not exhibit any significant variation in

123 expression among the samples. The amplification conditions were $3 \mathrm{~min}$ at $95^{\circ} \mathrm{C}$ and 45 cycles of $30 \mathrm{~s}$ at

$12495^{\circ} \mathrm{C}, 1 \mathrm{~min}$ at $60^{\circ} \mathrm{C}$. Real-time PCR analytical performance is detailed in Mazurais et al., (2008). To

125 determine the relative quantity of the studied gene transcripts present in the different samples, expression

126 ratios were calculated using a reference sample from the VD-0 group.

\section{$128 \quad$ 2.4. Statistics}

129 Results are expressed as means \pm S.D. Data arisen from experiments (survival, growth, ossification,

130 enzymatic assays and gene expression) were analysed by one-way ANOVA with Statview software

131 followed by the Newman-Keuls test when significant differences were found at $\mathrm{P}<0.05$. Additionally,

132 ANOVA two ways-analyse, followed by the Newman-Keuls test when significant differences were found

133 at the $\mathrm{P}<0.05$, were also carried out for gene expression data. G statistic was applied to test the

134 significance of the effect of dietary $\mathrm{VD}_{3}$ on the deformity rates (Sokal \& Rohlf 1981). The same test was 
135 used post-hoc to test the significance of the difference of the deformity rates between the different 136 regimes applied.

\section{Results}

\subsection{Larval performance}

141 All of the experimental feeds were efficiently ingested by the larvae. There were no significant

142 differences in survival rates between groups (Table 3). In terms of weight, the VD-0 presented

143 statistically significant lower weight than VD-1 (control) on day $45(\mathrm{P}<0.05)$. The rest of the groups did 144 not display differences statistically significant.

145 Appeared skeletal deformities consisted of kyphosis, scoliosis (vertebral column), pugheadness, or light 146 curvatures of the branchiostegal rays (skull), as well as deformities of the caudal-fin supporting elements

147 (fusions, displacements, extra formation or breaking of hypurals, epurals and vertebral processes; Fig. 1).

148 Dietary $\mathrm{VD}_{3}$ significantly affected the frequency of all deformities, except scoliosis (Fig. 2). The response 149 pattern of deformity frequencies was dependant on the deformity type (Fig. 2). Specifically, vertebral and 150 branchiostegal deformities exhibited a U-shape response of deformity incidence against $\mathrm{VD}_{3}$ levels (Fig. 151 2A-C), whereas pugheadness and caudal-fin deformities were significantly favoured in the VD-0 group 152 (Fig. 2D-E).

153 The ossification level for 45 day-old larvae is represented in Table 3 in terms of surface of mineralised 154 bones per larval surface. The surface of mineralised bones in the VD-0 group was significantly lower than 155 in the other groups $(\mathrm{P}=0.001)$, the ossification level of larvae from VD-1 group being 3 times higher. The 156 increase of dietary $\mathrm{VD}_{3}$ level from VD-1 to VD-3 did not show differences statistically significant $157(\mathrm{P}>0.05)$.

\subsection{Enzymatic assays}

160 The ratio "pancreatic enzyme in intestinal segment/pancreatic enzyme in whole larvae", expressed as a 161 percentage, in larvae fed the different $\mathrm{VD}_{3}$ treatments, illustrates the secretion (Table 3 ). In 25 day-old 162 larvae, the higher ratio was found in the VD-1 group (52\%, $\mathrm{P}=0.006)$ followed by VD-2 and 3 groups, 163 that did not displayed statistically significant differences in trypsin activity (around $43 \%, \mathrm{P}=0.950$ ). The 164 lowest ratio for trypsin was observed in the VD-0 group (29\%, $\mathrm{P}=0.002)$. At $45 \mathrm{dph}$, there were no 
165 differences in trypsin activity between the dietary groups, the percentage reaching around $70 \%(\mathrm{P}=0.080)$.

166 An elevated ratio of $85 \%$ for amylase was observed in 25 day-old larvae control group, this amylase ratio

167 was progressively lowered to $76 \%$ with the dietary $\mathrm{VD}_{3}$ level increase, the differences being only 168 statistically different between VD-1 and 3 groups $(\mathrm{P}=0.011)$. The lowest ratio for amylase (66\%) was

169 detected in the VD-0 group ( $\mathrm{P}=0.0003)$. At $45 \mathrm{dph}, \mathrm{VD}-1$ to VD-3 groups displayed statistically similar 170 levels of amylase activity (between 85 and 92\%, $>>0.05$ ), while the ratio for amylase of the VD-0 group 171 remained very low $(66 \%, \mathrm{P}<0.001)$.

172 The ratio of AN and AP segmental activity in BBM related to a cytosolic enzyme LeuAla peptidase 173 indicates the developmental status of the enterocytes (Table 3). The AP/LeuAla ratio at 25 dph was 2 174 times higher in the control group $(\mathrm{P}=0.008)$ with respect to the rest of the dietary groups that showed the 175 same ratio among them $(\mathrm{P}>0.05)$. At $45 \mathrm{dph}$, there were no differences in the AP/LeuAla ratio between 176 the dietary treatments $(\mathrm{P}>0.05)$. The $\mathrm{AN} /$ LeuAla ratio at 25 and $45 \mathrm{dph}$ displayed the same tendency 177 observed for AP/LeuAla ratio. Thus, the AN/LeuAla ratio in the control group at $25 \mathrm{dph}$ was 2.6 time 178 higher than in the rest of the dietary groups $(\mathrm{P}=0.0001)$. At $45 \mathrm{dph}$, all dietary groups presented a 179 statistically similar AN/LeuAla ratio $(\mathrm{P}=0.176)$.

180

181 3.3. Gene expression

182 Two-ways ANOVA indicated that BMP-4 expression (Fig. 3) was constant during larval development in 183 the VD-0 group $(\mathrm{P}=0.275)$, while it decreased 2, 2.5 and 3 times from day 11 to day $22(\mathrm{P}<0.0001)$ in 184 VD-1, VD-2 and VD-3 groups, respectively. No statistical differences in BMP-4 expression were found 185 in any dietary treatment after day $22(\mathrm{P}=0.6132)$. One-way ANOVA revealed that BMP-4 expression was 186 significantly lower in $\mathrm{VD}_{3}-0$ group compared to VD-3 one, at days 11 and 45.

187 Two-ways ANOVA showed that VDR $\alpha$ expression (Fig. 4) decreased with larval development in VD-0 188 and VD-1 groups $(\mathrm{P}<0.0001)$. In VD-2 and VD-3 groups, VDR $\alpha$ expression remained constant until day 18922 and then decreased $(\mathrm{P}<0.05)$. One-way ANOVA at day 11 showed that the VD-1 group presented 1.8 190 times higher expression than the other groups $(\mathrm{P}=0.002)$. At day 22, VDR $\alpha$ expression increased with the 191 level of $\mathrm{VD}_{3}$ increase until VD-2 ( $\mathrm{P}=0.028$ between VD-0 and VD-2). The highest level of dietary $\mathrm{VD}_{3}$ 192 caused a decrease in VDR $\alpha$ expression ( $\mathrm{P}=0.017$ between VD-2 and VD-3) reaching the same level of 193 expression observed in the VD-0 group. 
194 With the exception of the VD-0 group that only showed a decrease in VDR $\beta$ expression from day 11 to 195 day 22 to remain constant afterwards, the rest of the groups displayed a decreasing level of VDR $\beta$

196 expression during larval development (two-ways ANOVA, $\mathrm{P}<0.0001$, Fig. 5). One-way ANOVA revealed at day 22 the lowest VDR $\beta$ expression value in VD-0 group while at day 45 the lowest amount

198 of VDR $\beta$ transcripts were detected in larval groups fed the highest dietary $\mathrm{VD}_{3}$ levels $(\mathrm{P}<0.05)$.

199 Osteocalcin expression (Fig. 6) increased in all dietary groups during the larval development (two-ways 200 ANOVA, $\mathrm{P}<0.0001)$. This increase was at $45 \mathrm{dph} 40,58,78$ and 112 times higher than at 22 dph in VD-

201 0, VD-1, VD-2 and VD-3 groups, respectively. One-way ANOVA showed at day 11 similar osteocalcin

202 expression in all groups $(\mathrm{P}=0.891)$. At day 22, the VD-1 group displayed the highest level of osteocalcin expression while the lowest one was observed in the VD-3 group ( $\mathrm{P}=0.011)$. At day 45, VD-1 to VD-3

204 groups displayed the same level of osteocalcin transcript that was significantly higher than that observed in group VD-0 $(\mathrm{P}=0.021)$.

206 With the exception of the VD-1 group that showed the same amount of transcript on days 22 and 45 (Fig.

207 7), TRPV6 expression increased during larval development in the rest of dietary groups (two-ways 208 ANOVA, $\mathrm{P}<0.0001)$. One-way ANOVA revealed that TRPV6 expression was not affected by the dietary $209 \mathrm{VD}_{3}$ level on days 11 and $45(\mathrm{P}=0.659)$. Interestingly, on day 22, the VD-1 group displayed the highest 210 level of TRPV6 expression $(\mathrm{P}=0.001)$.

\section{4. Discussion}

214 It is well known that European sea bass larvae perform adequately when fed on microdiets (Cahu et al.,

215 1998; Cahu \& Zambonino-Infante 2001), what offers the possibility of studying the effect of a concrete

216 nutrient on the development of the animal. This fact has allowed to perform the present work, where the

217 effects of dietary $\mathrm{VD}_{3}$ on the larval morphogenesis with special attention to bone ossification and the

218 development of skeletal deformities have been analysed. As the percentage of malformed specimens at

219 the end of the larval period remains still too elevated, a study leading to a better knowledge of the

220 physiological mechanisms involved in the skeletogenesis process influenced by nutritional factors is 221 certainly helpful. All dietary treatments were adequate to develop sea bass larvae in suitable conditions, 222 as confirmed by the high percentage of survival $(>45 \%)$ and growth level $(>35 \mathrm{mg}$ wet weight) at the 223 end of the larval phase (45 dph), which are in the considered acceptable range for marine fish larval 
rearing using compound diets (Cahu \& Zambonino-Infante 2001; Blair et al., 2003; Cahu et al., 2003).

Moreover, the larval performance (weight and survival) obtained in this experiment is comparable to the one achieved with live prey feeding still used in hatcheries (Person-Le Ruyet et al., 1993).

228 Skeletal deformities especially develop during the early ontogenetic stages due to unfavourable biotic factors, including nutrition (Koumoundouros et al., 1997, 2002; Villeneuve et al., 2005, 2006; Sfakianakis

230 et al., 2006; Georgakopoulou et al., 2007). As different skeletal elements form in different developmental stages (Koumoundouros et al., 2000; Lewis-McCrea et al., 2004) and environmental preferences change

232 rapidly during ontogeny, it has been reasonably suggested, and in many cases shown, that the response against biotic/environmental factors is not the same for the different skeletal elements and therefore

234 deformities (Koumoundouros et al., 1997, 2002; Sfakianakis et al., 2006; Georgakopoulou et al., 2007). In the present paper two distinct response patterns were presented against the $\mathrm{VD}_{3}$ gradient. In the first,

236 vertebral and branchiostegal deformities were maximised at both the extreme levels of the tested $\mathrm{VD}_{3}$ range (VD-0 and VD-3 groups) (Fig. 1A-C), whereas in the second pattern, pugheadness (deformed maxillary and premaxillary elements) and caudal-fin deformities were maximised at only the lower $\mathrm{VD}_{3}$ level tested (VD-0 group) (Fig. 1D-E). These results could suggest that skeletal elements developed at the early developmental stages (jaw and caudal elements) (Gluckmann et al., 1999; Koumoundouros et al., 2001) are more resistant to the high $\mathrm{VD}_{3}$ levels than those developing in the later stages (vertebrae and branchiostegal rays) (Marino et al., 1993).

244 The present study revealed for the first time an impact of dietary $\mathrm{VD}_{3}$ on the sea bass digestive system ontogenesis. Results clearly indicated that $27.6 \mathrm{IU} / \mathrm{g} \mathrm{VD} 3$ (VD-1) induced an earlier maturation of

246 digestive function than the other treatments. The delay of the digestive system maturation in the VD-0,

247 VD-2 and VD-3 groups was revealed by the lowest digestive enzyme secretion (amylase and trypsine) as

248 well as by the lowest levels of the indicators of intestinal maturation (AP/LeuAla and AN/LeuAla) 249 detected.

250 As intestine is involved in calcium absorption through the epithelial calcium channels (Nijenhuis et al., 251 2005), it was next sought to determine whether the observed intestinal maturation delay was correlated to 252 a modulation of TRPV6 expression, the major transcellular mediator of $\mathrm{Ca}^{2+}$ uptake from the intestinal 253 lumen (Hoenderop et al., 2005). Interestingly, the present results indicated that the levels of TRPV6 
expression in sea bass from $22 \mathrm{dph}$ were correlated to the intestinal maturation degree. The VD-1 group displayed around that time the best indicators of intestinal maturation in concomitance with the highest

256 level of TRPV6 gene expression. Since $\mathrm{Ca}^{2+}$ is necessary for bone mineralization and this probably influenced the following pathways involving the $\mathrm{VD}_{3}$ on the ossification process, bone mineralization was monitored by the analyses of osteocalcin expression. Osteocalcin is one of the marker genes for the progression of osteoblastic differentiation, being associated with mineralization of the extracellular matrix

260 (Lian \& Stein 1995). As expected, there was a good correlation between osteocalcin and TRPV6, both 261 showing the same pattern of gene expression during development, with the exception of the VD-1 group 262 that reached the maximun amount of TRPV6 transcripts earlier than the other groups (at $22 \mathrm{dph}$ ). 263 Moreover, TRPV6 and osteocalcin displayed a similar gene expression pattern between treatments at 11 264 and $22 \mathrm{dph}$. This result revealed that the consequences of dietary $\mathrm{VD}_{3}$ effects on digestive system development were reflected at bone level. Indeed, low (VD-0 group) and high dietary $\mathrm{VD}_{3}$ levels (VD-2 and VD-3 groups) displayed at 22 dph lower levels of TRPV6 and osteocalcin expression than the control group (VD-1). Then, the probably less amount of $\mathrm{Ca}^{2+}$ absorbed together with the low level of osteocalcin expression could induce a poor mineralization. Additionally, this developmental phase corresponded in sea bass larvae to the beginning of column ossification, therefore being predisposed to the appearance of skeletal malformations. At 45 dph, all dietary groups could acquire similar intestinal maturation and TRPV6 expression level to the VD-1 group, while osteocalcin expression remained lower in the VD-0

272 group generating larvae with a poorly mineralized skeleton. Surprisingly, VD-2 and VD-3 groups were somehow able to reach the end of the larval phase with a comparable amount of osteocalcin transcripts to

274 that of the control group (VD-1). In order to understand these findings, the study of other molecular actors operating into the $\mathrm{VD}_{3}$ pathway such as VDRs and BMP-4 were contemplated.

Since $\mathrm{VD}_{3}$ stimulates the expression of TRPV6 and osteocalcin genes through binding of their receptor

278 (VDR) on the vitamin D responsive element (Yeung et al., 2002; Meyer et al., 2006), it was hypothesized that the regulation of TRPV6 and osteocalcin observed could be associated to a modulation of the VDR

280 expression. Indeed, the tendency observed at $11 \mathrm{dph}$ in $\operatorname{VDR} \beta$ expression among the different dietary groups was also found in Osteocalcin and TRPV6 expression at $22 \mathrm{dph}$. Equally, the pattern of VDR $\beta$ expression observed at 22 dph was detected in osteocalcin expression at 45 dph but not in TRPV6.

283 Although the relation of genes expression was evident, the temporal gap existent between them cannot be 
explained but could likely reveal the involvement of an intermediate actor. These results suggested that the level of VDR $\beta$ expression influenced the level of osteocalcin transcripts and, consequently, the level 286 of bone mineralization, as revealed by the red-alizarin coloration analyses. Moreover, it could be observed that the amount of VDRs and osteocalcin transcripts in the VD-0 group did not change from 22 to $45 \mathrm{dph}$ indicating a disruption in the skeletogenesis process. Such ossification disorder was detected even earlier via the BMP-4 pathway. BMP-4 is involved in the achievement of the mature phenotype of osteoblasts, which is crucial for bone mineralization. In the present study, the influence of BMP-4 on sea bass larval morphogenesis took place during the early stage of development exhibiting at $11 \mathrm{dph}$ the

292 highest expression level of the larval period. At this developmental age, BMP-4 expression decreased with the descent of dietary $\mathrm{VD}_{3}$ level, in line with the tendency observed by Mazurais et al., (2008) in a

294 previous work using different doses of dietary VM. Since BMP-4 is involved on the differentiation of bipotent osteoblast-adipocyte cells from bone marrow into osteoblasts in developing sea bass larvae

296 (Mazurais et al., 2008), the low level of BMP-4 expression detected in larvae from VD-0 group could negatively influence the availability of potentially osteoblastic cells leading to an ossification delay, as revealed by red-alizarin coloration of bones at $45 \mathrm{dph}$, and an increase of the malformation rate.

300 As stated before, larvae from VD-2 and VD-3 groups were unexpectedly able to achieve at 45 dph the same ossification level of the VD-1 group considering their intestinal maturation degree at $22 \mathrm{dph}$.

302 Together with the osteocalcin expression increase, the lower expression level of VDR $\beta$ observed at 45 303 dph in VD-2 and VD-3 groups compared to the control group (VD-1) could indicate that osteoblasts 304 differentiation for bone mineralization was more stimulated in larvae fed the higher $\mathrm{VD}_{3}$ levels. Indeed, 305 the present study showed an inverse pattern of VDRs and osteocalcin expression during sea bass

306 ontogenesis; while VDRs expression decreased, osteocalcin expression increased as a response of the 307 mineralization process. This result was in accordance with the fact that during the early stages of 308 osteoblastogenesis, $\mathrm{VD}_{3}$ initially inhibits osteoblast differentiation through VDR-signalling and 309 subsequently increases osteoblast activity in terminally differentiated cells (St-Arnaud 2008), leading to 310 the beginning of osteocalcin expression at late stages of the osteoblast differentiation (Lian \& Stein 1995;

311 Shi et al., 2007). The high rate of mineralization could likely culminate in the high percentage of 312 branchiostegal and column malformations observed in VD-2 and VD-3 groups. Nevertheless, to 313 understand the processes occurred between 22 and $45 \mathrm{dph}$, deeper studies of the molecular mechanisms 
314 acting under high dietary $\mathrm{VD}_{3}$ doses need to be attempted. In mammals, osteocytes are the most abundant

315 cells in bone tissue and act as sentinel cells implied in bone remodelling and turnover by controlling the

316 function of osteoblasts and osteoclasts (Noble, 2008). However, in advanced teleosts such as sea bass,

317 osteocytes are absent, being this function attributed to the osteoclasts (Witten \& Huysseune, 2009). In this

318 sense, regarding the obtained results in terms of gene expression and skeletal malformations, the way

319 osteoclasts are implicated on the regulation of bone mineralization and on the physiological response of

320 sea bass larvae to such dietary $\mathrm{VD}_{3}$ levels will be further explored.

322 Results of VDR expression could indicate that requirements in $\mathrm{VD}_{3}$ change during the sea bass larval

323 development depending on the differentiation state of bone cells. The current study demonstrates, on the

324 one hand, that a dietary $\mathrm{VD}_{3}$ deficiency had serious consequences on the sea bass larval ontogenesis, that

325 is, a delay on growth, digestive system development and skeletogenesis, which was traduced in the

326 appearance of skeleton disorders at the end of the larval period. On the other hand, larger doses of $\mathrm{VD}_{3}$

327 than $27.6 \mathrm{IU} / \mathrm{g}$ diet did not induce better larval performance and, additionally, it would suppose an

328 economical squander for the aquaculture industry. Among the range of $\mathrm{VD}_{3}$ levels analysed, $27.6 \mathrm{IU}$

$329 \mathrm{VD}_{3} / \mathrm{g}$ diet (VD-1) gave the best results of sea bass larval morphogenesis, even though the percentage of

330 malformed larvae remained elevated. It is worth to be noted that the control diet (VD-1) used in the

331 current study incorporated $8.4 \mathrm{IU} \mathrm{VD}_{3} / \mathrm{g}$ diet more than that recommended for fish larvae and is 11.5

332 times higher than the amount recommended for juveniles (NRC, 1993). These new findings reveal the

333 necessity, in a short future, to analyze the different forms of vitamin D in larvae, in order to evaluate the

334 real amount of bio-available vitamin $\mathrm{D}_{3}$. A possible and practical consequence of this could be a revision

335 of $\mathrm{VD}_{3}$ requirements in developing marine fish larvae.

336

\section{Conclusions}

339 The present study revealed that sea bass larvae are extremely sensitive to the dietary $\mathrm{VD}_{3}$ level. The

340 current results suggested that the suitable $\mathrm{VD}_{3}$ level for an optimum larval development is in between a

341 restricted range and subtitles variations could unleash severe physiological disruptions in cascade, (1)

342 disruption of the BMP-4 pathway, (2) delayed maturation of the intestinal functions, (3) with negative 
consequences on $\mathrm{Ca}^{+2}$ absorption and bone mineralization, (4) leading to the appearance of skeletal deformities.

\section{Acknowledgements}

348 The authors are grateful to Mrs Viviane Verlhac from DSM Nutritional Products-France who kindly 349 provided all the vitamins used in this work. The authors also thank Hervé Le Delliou for the diet analyses and Ms. Vagiani G. and Ms. Georga I. for their involvement in the analysis of bone deformities. This work was, in part, supported by FINEFISH, a Collective Research Project of the sixth Framework Programme of the European Union (Contract 012451). M.J. Darias was supported by a postdoctoral fellowship from the Fundación Ramón Areces (Spain).

\section{References}

356

Blair, T., Castell, J., Neil, S., D'Abramo, L., Cahu, C., Harmon, P., Ogunmoye, K., 2003. Evaluation of microdiets versus live feeds on growth, survival and fatty acid composition of larval haddock (Melanogrammus aeglefinus). Aquaculture 225, 451-461.

Bradford, M.M., 1976. A rapid and sensitive method for the quantitation of microgram quantities of protein utilizing the principle of protein-dye binding. Anal. Biochem. 72, 248-254.

Bessey, O.A., Lowry, O.H., Brock, M.J., 1946. Rapid coloric method for determination of alcaline phosphatase in five cubic millimeters of serum. J. Biol. Chem. 164, 321-329.

367 Cahu, C.L., Zambonino-Infante, J.L., 1994. Early weaning of sea bass Dicentrarchus labrax larvae with a compound diet, effect on digestive enzymes. Comp. Biochem. Physiol. 109, 213-222.

370 Cahu, C.L., Zambonino-Infante, J. L., 2001. Substitution of live food by formulated diets in marine fish 
373 Cahu, C.L., Zambonino-Infante, J.L., Escaffre, A.M., Bergot, P., Kaushik, S., 1998. Preliminary results 374 on sea bass (Dicentrarchus labrax) larvae rearing with compound diet from first feeding. Comparison 375 with carp (Cyprinus carpio) larvae. Aquaculture 169, 1-7.

376 Cahu, C.L., Takeuchi, T., Zambonino Infante, J.L., 2003. Nutritional components affecting skeletal 377 development in fish larvae. Aquaculture 227, 245-258.

378

379 Cahu, C.L., Zambonino-Infante, J.L., Barbosa, V., 2003. Effect of dietary phospholipid level and 380 phospholipid,neutral lipid value on the development of sea bass (Dicentrarchus labrax) larvae fed a 381 compound diet. Br. J. Nutr. 90, 21-8.

382

383 Crane, R.K., Boge, G., Rigal, A., 1979. Isolation of brush border membranes in vesicular form from the intestinal spiral valve of the small dogfish (Scyliorhinus canicula). Biochim. Biophys. Acta 554, 264-267.

Dedi, J., Takeuchi, T., Seikai, T., Watanabe, T., Hosoya, K., 1997. Hypervitaminosis A during vertebral morphogenesis in larval Japanese flounder. Fisheries Sci. 63, 466-473.

388

389 DeLuca, H.F., 2004. Overview of general physiologic features and functions of vitamin D. Am. J. Clin.

390 Nutr. 80, 1689S-96S.

391

392 Fernández, I., Hontoria, F., Ortiz-Delgado, J.B., Kotzamanis, Y., Estévez, A., Zambonino-Infante, J.L.,

393 Gisbert, E., 2008. Larval performance and skeletal deformities in farmed gilthead sea bream (Sparus

394 aurata) fed with graded levels of Vitamin A enriched rotifers (Brachionus plicatilis). Aquaculture 283, $395 \quad 102-115$.

397 Fernández, I., Pimentel, M., Ortiz-Delgado, J.B., Hontoria, F., Sarasquete, C., Estévez, A., Zambonino-

398 Infante, J.L., Gisbert, E., 2009. Effect of dietary vitamin A on Senegalese sole (Solea senegalensis)

399 skeletogenesis and larval quality. Aquaculture 295, 250-265. 

(Dicentrarchus labrax) larvae fed from first feeding on compound diets containing medium-chain triacylglycerols. Aquaculture 190, 261-271.

404

405 Georgakopoulou, E., Angelopoulou, A., Kaspiris, P., Divanach, P., Koumoundouros, G., 2007.

406 Temperature effects on cranial deformities in European sea bass, Dicentrarchus labrax (L.). J. Appl.

407 Ichthyol. 23, 99-103.

408

409 Gisbert, E., 2007. Efecto de la dieta sobre la calidad de larvas de peces. In Actas del XI Congreso

$410 \quad$ Nacional de Acuicultura vol II, pp. 1111-1118.

411 Gluckmann, I., Huriaux, F., Focant, B., Vandewalle, P., 1999. Postembryonic development of the

412 cephalic skeleton in Dicentrarchus labrax (Pisces, Perciformes, Serranidae). Bull. Mar. Sci. 65, 11-36.

413

414 Haga, Y., Takeuchi, T., Murayama, Y., Ohta, K., Fukunaga, T., 2004. Vitamin $\mathrm{D}_{3}$ compounds induce 415 hypermelanosis on the blind side and vertebral deformity in juvenile Japanese flounder Paralichthys 416 olivaceus. Fisheries Sci. 70, 59-67.

417

418 Hoenderop, J.G.J., Nilius, B., Bindels, R.J.M., 2005. Calcium Absorption Across Epithelia. Physiol. Rev. $419 \quad 85,373-422$

420

421 Holm, H., Hanssen, L.E., Krogdahl, A., Florholmen, J., 1988. High and low inhibitor soybean meals 422 affect human duodenal proteinase activity differently, in vivo comparison with bovine serum albumin. J. 423 Nutr. 118, 515-520.

424

425 Karperien, M., Hamersma, H., Papapoulos, S.E., ten Dijke, P., Löwik, C.W., 2004. Sclerostin is an 426 osteocyte-expressed negative regulator of bone formation, but not a classical BMP antagonist. J. Exp.

427 Med. 199, 805-14. 

deformity in intensive gilthead sea bream (Sparus aurata L.) larviculture. Moment of apparition and description. Aquaculture 156, 165-177.

432

433 Koumoundouros, G., Divanach, P., Kentouri, M., 2000. Development of the skull in Dentex dentex 434 (Osteichthyes, Sparidae). Mar. Biol. 136, 175-184.

435

436 Koumoundouros, G., Divanach, P., Anezaki, L.,, Kentouri, M., 2001. Temperature-induced ontogenetic 437 plasticity in sea bass (Dicentrarchus labrax). Mar. Biol. 139, 817-830.

438

439 Koumoundouros, G., Maingot, E., Divanach, P., Kentouri, M., 2002. Kyphosis in reared sea bass 440 (Dicentrarchus labrax L.), Ontogeny and effects on mortality. Aquaculture 209, 49-58.

441 Lall, S.P., Lewis-McCrea, L., 2007. Role of nutrients in skeletal metabolism and pathology in fish, an overview. Aquaculture 267, 3-19.

444 Lewis-McCrea, L.M., Lall, S.P., Eckhard, W.P., 2004. Morphological descriptions of the early stages of 445 spine and vertebral development in hatchery-reared larval and juvenile Atlantic halibut (Hippoglossus hippoglossus). Aquaculture 241, 47-59.

448 Lian, J.B., Stein, G.S., 1995. Development of the osteoblast phenotype, molecular mechanisms mediating osteoblast growth and differentiation. Iowa Orthop. J. 15,118-140.

450

451 Marino, G., Boglione, C., Bertolini, B., Rossi, A., Ferreri, F., Cataudella, S., 1993. Observations on 452 development and anomalies in the appendicular skeleton of sea bass, Dicentrarchus labrax L. 1758, 453 larvae and juveniles. Aquac. Fisher. Manag. 24, 445-456.

455 Maroux, S., Louvard, D., Baratti, J., 1973. The aminopeptidase from hog-intestinal brush border. 456 Biochim. Biophys. Acta 321, 282-295.

457 Mazurais, D., Darias, M.J., Gouillou-Coustans, M.F., Le Gall, M.M., Huelvan, C., Desbruyères, E., 458 Quazuguel, P., Cahu, C., Zambonino-Infante, J.L., 2008. Dietary vitamin mix levels influence the 
ossification process in European sea bass (Dicentrarchus labrax) larvae. Am. J. Physiol. Regul. Integr. Comp. Physiol. 294, R520-7.

461

462

Métais, P., Bieth, J, 1968. Détermination de l'a-amylase par une microtechnique. Ann. Biol. Clin. 26, 463 $133-142$.

464

465

Meyer, M.B., Watanuki, M., Kim, S., Shevde, N.K., Pike, W.J., 2006. The human TRPV6 distal promoter

466 contains multiple vitamin $\mathrm{D}$ receptor binding sites that mediate activation by 1,25 -Dihydroxyvitamin $\mathrm{D}_{3}$

467 in intestinal cells. Mol. Endocrinol. doi,10.1210.

468

469

National-Research-Council., 1993. Nutrient requirements of fish. Washington DC, National Academy

470 Press.

471

National-Research-Council., 1996. Guide for the care and use of the laboratory animals. Washington DC,

472

National Academic Press.

473

474

Nicholson, J.A., Kim, Y.S., 1975. A one-step L-amino acid oxidase assay for intestinal peptide hydrolase 475 activity. Anal. Biochem. 63, 110-117.

476

477

Nijenhuis, T., Joost, Æ., Hoenderop, G.J., Bindels, R.J.M., 2005. TRPV5 and TRPV6 in Ca2+ (re)absorption, regulating Ca2+ entry at the gate. Eur. J. Physiol. 451, 181-192.

479

480

Noble BS., 2008. The osteocyte lineage. Arch. Biochem. Biophys. 473, 106-111.

481

482

Person-Le Ruyet, J., Alexandre, J.C., Thébaud, L., Mugnier, C., 1993. Marine fish larvae feeding, 483 formulated diets or live preys? J. World Aquacult. Soc. 24, 211-224.

484

485

Sfakianakis, D.G., Georgakopoulou, E., Papadakis, I.E., Divanach, P., Kentouri, M., Koumoundouros, G.,

486 2006. Environmental determinants of haemal lordosis in European sea bass, Dicentrarchus labrax 

continuous activation of vitamin D and Wnt response pathways on osteoblastic proliferation and differentiation. Bone 41, 87-96.

492

Sokal, R.R., Rohlf, F.J., 1981.Biometry, the Principles and Practice of Statistics in Biological Research. New York, W.H. Freeman.

St-Arnaud, R., 2008. The direct role of vitamin D on bone homeostasis. Arch. Biochem. Biophys. 473, 225-230.

498

Sutton, A.L., Zhang, X., Ellison, T.I., Macdonald, P.N., 2005. The 1,25(OH $)_{2} \mathrm{D}_{3}$-regulated transcription factor MN1 stimulates vitamin D receptor-mediated transcription and inhibits osteoblastic cell proliferation. Mol. Endocrinol. 19, 2234-44.

502

503

Takeuchi, T., Dedi, J., Haga, Y., Seikai, T., Watanabe, T., 1998. Effect of vitamin A compounds on bone deformity in larval Japanese flounder (Paralichthys olivaceus). Aquaculture 169, 155-165.

Villeneuve, L., Gisbert, E., Le Delliou, H., Cahu, C. L., Zambonino-Infante, J.L., 2005. Dietary levels of all-trans retinol affects retinoid nuclear receptor expression and skeletal development in European sea bass larvae. Brit. J. Nutr. 93, 791-801.

510 Villeneuve, L., Gisbert, E., Moriceau, J., Cahu, C., Zambonino-Infante, J.L., 2006. Intake of different

511 levels of vitamin A and polyunsaturated fatty acids during different developmental periods modifies the

512 expression of morphogenesis genes in European sea bass (Dicentrarchus labrax). Brit. J. Nutr. 95, 677-

513687.

515 Witten, P.E. \& Huysseune, A., 2009. A comparative view on mechanisms and functions of skeletal

516 remodelling in teleost fish, with spetial emphasis on osteoclasts and their function. Biological Reviews 84 $517 \quad 315-346$. 
519 Yeung, F., Law, W.K., Yeh, C.H., Westendorf, J.J., Zhang, J., Wang, R., Kao, C., Chung, L.W.K., 2002.

520 Regulation of Human Osteocalcin Promoter in Hormoneindependent Human Prostate Cancer Cells. J.

521 Biol. Chem. 277, 2468-2476.

522

523 Zambonino-Infante, J.L., Cahu, C.L., Péres, A., Quazuguel, P., Le Gall, M.M., 1996. Sea bass

524 (Dicentrarchus labrax) larvae fed different Artemia rations, growth, pancreas enzymatic response and 525 development of digestive functions. Aquaculture 139, 129-138.

526

527 Zambonino-Infante, J.L., Cahu, C.L., Péres, A., 1997. Partial substitution of di- and tripeptides for native 528 proteins in sea bass diet improves Dicentrarchus labrax larval development. J. Nutr. 127, 608-614. 

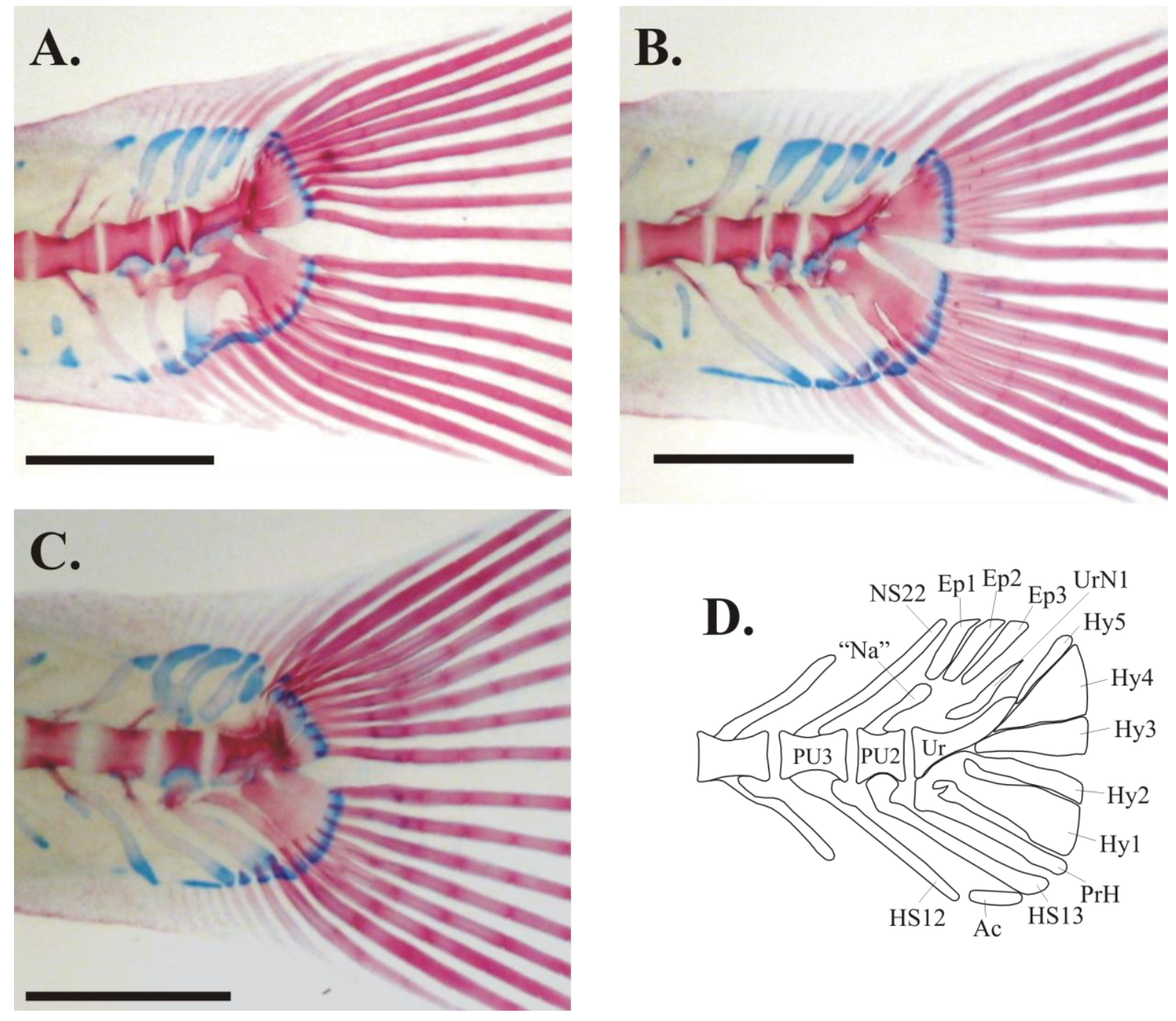

Figure 1. Variations of the caudal fin deformities (A-C). D, Normal anatomy of the caudal-fin supporting elements. Ac, accessory cartilage; Ep, epurals; HS, haemal processes; Hy, hypurals; "Na", modified neural arch of PU2. NS, neural processes; PrH, parhypural; PU, preural centra; Ur, urostyle; UrN1, uroneural 1. Scale bars are equal to $1.0 \mathrm{~mm}$. (Alizarin Red $\mathrm{S}$, Alcian Blue stain) 
Figure 2. Effect of dietary vitamin $\mathrm{D}_{3}$ on the development of skeletal deformities in sea bass larvae. A, kyphosis. B, scoliosis. C, light deformities of the branchiostegal rays. D, pugheadness. E, light deformities of the caudal fin. Error bars equal to 1 S.D. Same letters indicate significant differences $(\mathrm{P}<0.05$, G-test $)$.
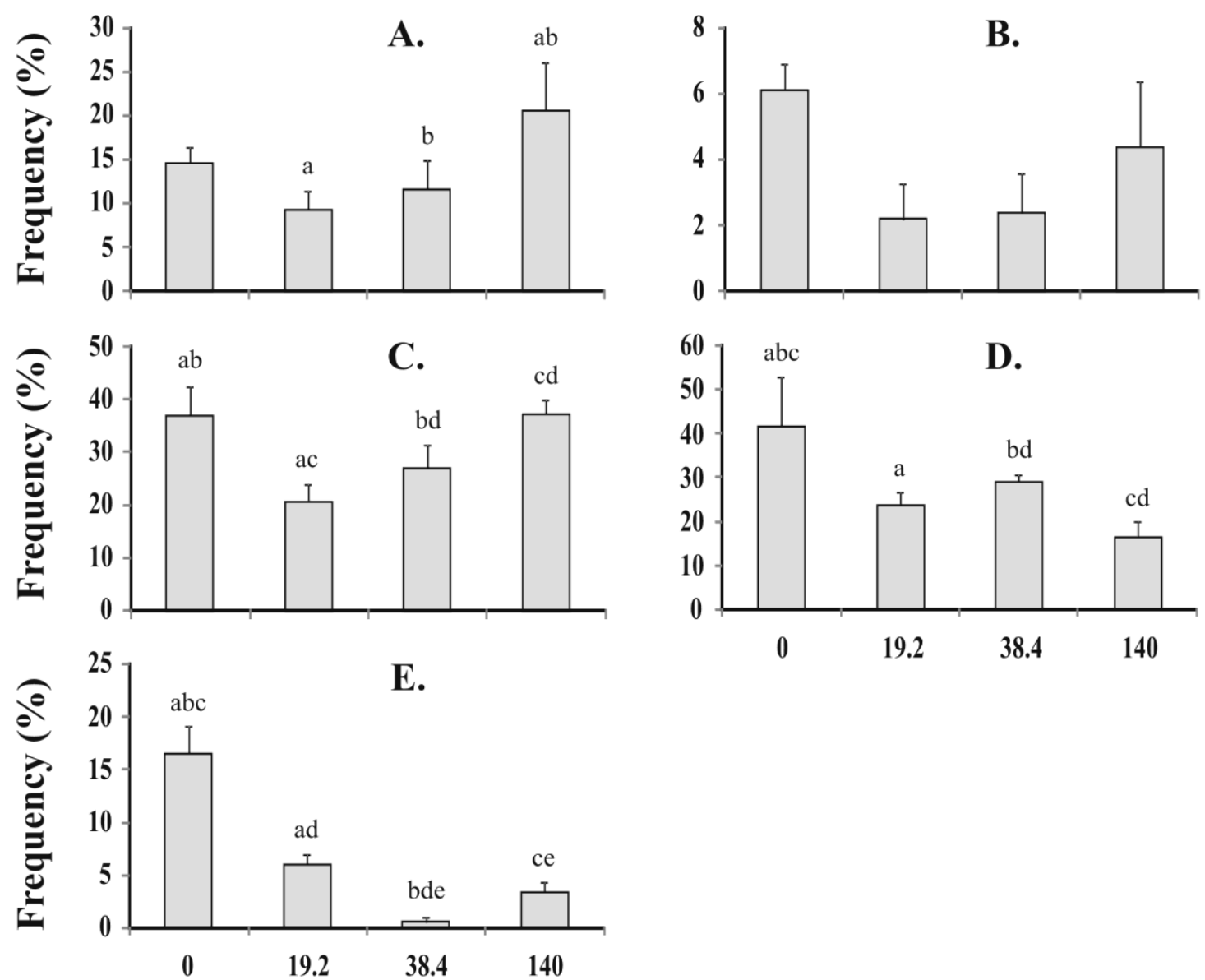

Dietary Vitamin $D_{3}(I U / g)$ 
Figure 3. Relative expression of BMP-4 gene during the development of sea bass larvae fed the different experimental diets. Data are represented as means \pm S.D. $(n=4)$. Values with a different superscript letter denote significant differences between groups at the same date (One-way ANOVA, $\mathrm{P}<0.05$ ). Values with different number of asterisks indicate significant differences between days for the same dietary treatment (Two-ways ANOVA, $\mathrm{P}<0.0001)$. NS, non significant.

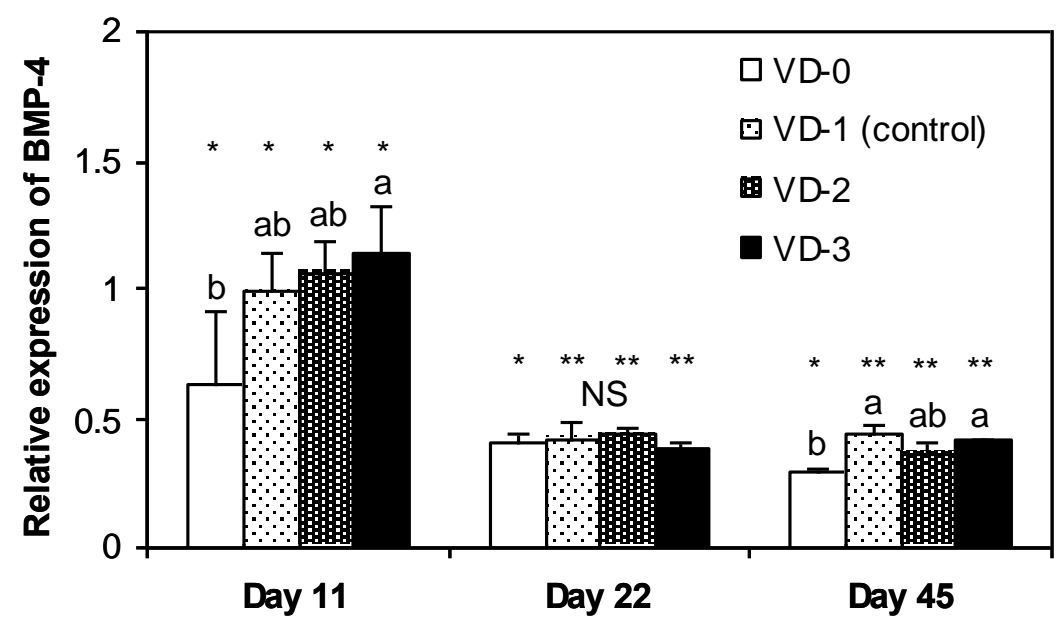


Figure 4. Relative expression of the VDR-alpha gene during the development of sea bass larvae fed the different experimental diets. Data are represented as means \pm S.D. $(n=4)$. Values with a different superscript letter denote significant differences between groups at the same date (One-way ANOVA, $\mathrm{P}<0.05$ ). Values with different number of asterisks indicate significant differences between days for the same dietary treatment (Two-ways ANOVA, $\mathrm{P}<0.0001$ ).

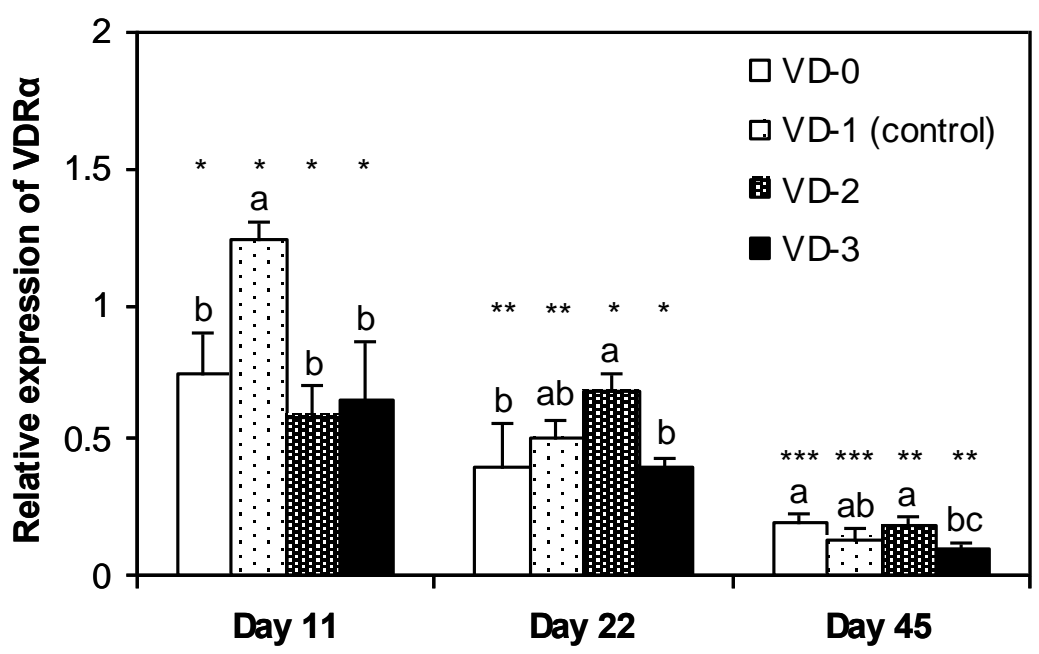


Figure 5. Relative expression of the VDR-beta gene during the development of sea bass larvae fed the different experimental diets. Data are represented as means \pm S.D. $(n=4)$. Values with a different superscript letter denote significant differences between groups at the same date (One-way ANOVA, $\mathrm{P}<0.05$ ). Values with different number of asterisks indicate significant differences between days for the same dietary treatment (Two-ways ANOVA, $\mathrm{P}<0.0001)$.

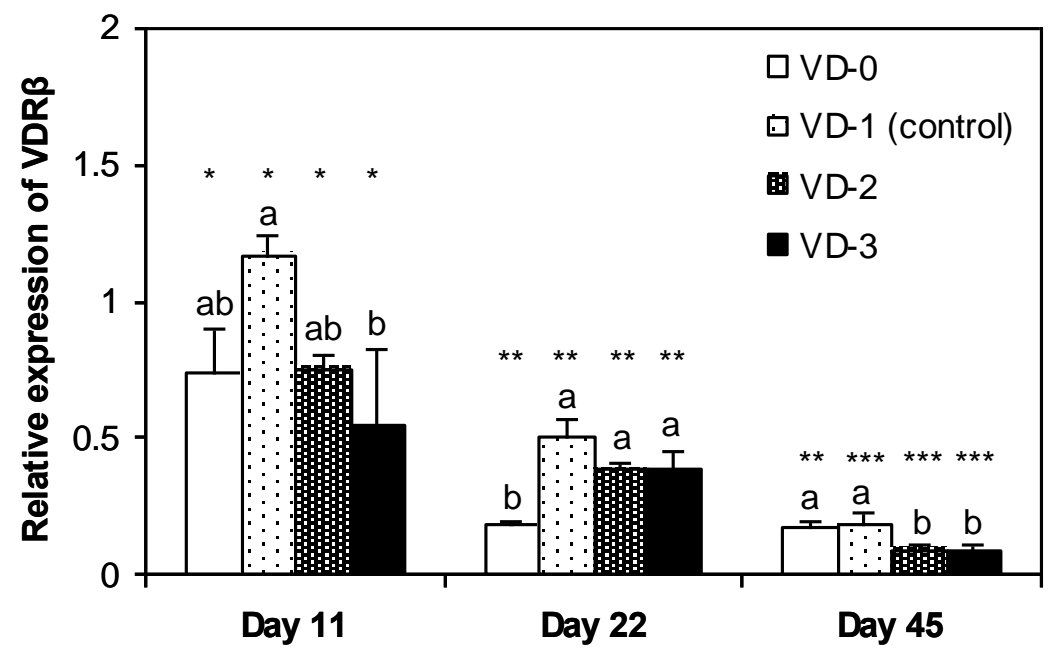


Figure 6. Relative expression of the Osteocalcin gene during the development of sea bass larvae fed the different experimental diets. Data are represented as means \pm S.D. $(n=4)$. Values with a different superscript letter denote significant differences between groups at the same date (One-way ANOVA, $\mathrm{P}<0.05$ ). Values with different number of asterisks indicate significant differences between days for the same dietary treatment (Two-ways ANOVA, $\mathrm{P}<0.0001$ ). NS, non significant.

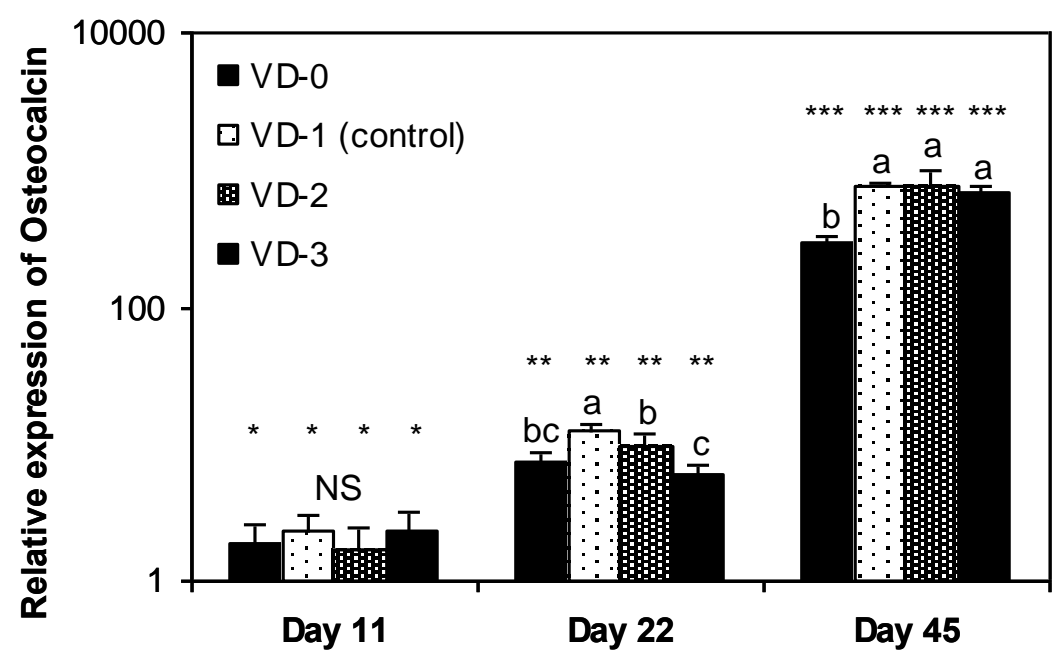


Figure 7. Relative expression of the TRPV6 gene during the development of sea bass larvae fed the different experimental diets. Data are represented as means \pm S.D. $(n=4)$. Values with a different superscript letter denote significant differences between groups at the same date (Oneway ANOVA, $\mathrm{P}<0.05)$. Values with different number of asterisks indicate significant differences between days for the same dietary treatment (Two-ways ANOVA, $\mathrm{P}<0.0001$ ). NS, non significant.

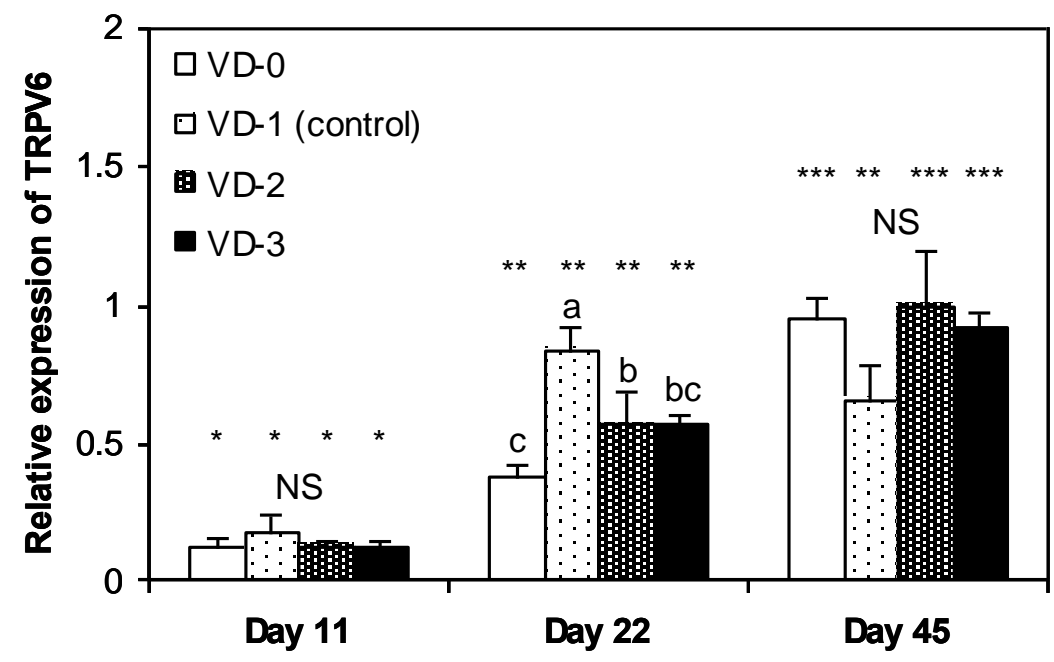


Table 1. Composition (in \%) of the diets

\begin{tabular}{|c|c|c|c|c|}
\hline & VD- 0 & VD-1 & VD-2 & VD-3 \\
\hline \multicolumn{5}{|l|}{ Ingredients $^{\mathrm{a}}$} \\
\hline Defatted fish meal ${ }^{\mathrm{b}}$ & 52.0 & 52.0 & 52.0 & 52.0 \\
\hline Fish meal hydrolysate & 14.0 & 14.0 & 14.0 & 14.0 \\
\hline Soy lecithin & 7.0 & 7.0 & 7.0 & 7.0 \\
\hline Marine lecitihin & 14.0 & 14.0 & 14.0 & 14.0 \\
\hline Concentrated $\mathrm{VM}^{\mathrm{c}}$ & 4.0 & 4.0 & 4.0 & 4.0 \\
\hline Vitamin $\mathrm{D}_{3}{ }^{\mathrm{d}}$ & 0.0 & 19.2 & 38.4 & 140 \\
\hline Mineral mix ${ }^{\mathrm{e}}$ & 4.0 & 4.0 & 4.0 & 4.0 \\
\hline Betaine & 1.0 & 1.0 & 1.0 & 1.0 \\
\hline Cellulose & 4.0 & 4.0 & 4.0 & 4.0 \\
\hline \multicolumn{5}{|l|}{ Proximal composition } \\
\hline Dry matter & 88.9 & 89.0 & 89.1 & 89.3 \\
\hline Proteins & 62.8 & 61.4 & 63.0 & 61.7 \\
\hline Lipids & 19.6 & 20.3 & 19.4 & 20.6 \\
\hline Neutral lipids & 7.5 & 6.7 & 5.6 & 6.0 \\
\hline Phospholipids & 15.5 & 16.5 & 13.3 & 14.3 \\
\hline Vitamin $\mathrm{D}_{3}{ }^{\mathrm{f}}$ & 11.2 & 27.6 & 42 & 120 \\
\hline
\end{tabular}

${ }^{a}$ All dietary ingredients were obtained commercially. Fish meal hydrolysate CPSP 90:10\% lipids; Soluble Fish Protein Concentrate (SopropÊche, Boulogne sur Mer, France); soy lecithin (Ets Louis François, St Maur des Fossés, France); marine lecithin LC 60 (Phosphotech, St Herblain, France). ${ }^{b}$ Defatted in the laboratory using Norse LT 94 fish meal (La Lorientaise, Lorient, France). ${ }^{\mathrm{c}}$ Composition per kilogram of the vitamin mixture: choline chloride $60 \%, 333 \mathrm{~g}$; vitamin A acetate, (500 $000 \mathrm{UI} / \mathrm{g}) 1 \mathrm{~g}$; vitamin E (500 UI/g) 20 g; vitamin B3 2 g, vitamin B5 4 g; vitamin B1 200 mg; 
vitamin B2 80\%, 1 g; vitamin B6 600 mg; vitamin C 35\%, 28.6 g; vitamin B9 80\%, $250 \mathrm{mg}$; vitamin concentrate B12 (10 g/kg), $0.2 \mathrm{~g}$; biotin, $1.5 \mathrm{~g}$; vitamin $\mathrm{K} 351 \%, 3.92$ g; meso-inositol $60 \mathrm{~g}$; cellulose, $543.3 \mathrm{~g}$. ${ }^{\mathrm{d}}$ Amount of vitamin $\mathrm{D}_{3}$ incorporated per gram of the diet: VD-0, $0 \mathrm{IU} / \mathrm{g} ; \mathrm{VD}-1$ (control), $19.2 \mathrm{IU} / \mathrm{g} ; \mathrm{VD}_{3}-2,38.4 \mathrm{IU} / \mathrm{g} ; \mathrm{VD}_{3}-3$, $140 \mathrm{IU} / \mathrm{g}$. ${ }^{\mathrm{e}}$ Composition per kilogram of the mineral mixture: $90 \mathrm{~g} \mathrm{KCl}, 40 \mathrm{mg} \mathrm{KIO}$, $500 \mathrm{~g} \mathrm{CaHPO}_{4} 2 \mathrm{H}_{2} \mathrm{O}, 40 \mathrm{~g} \mathrm{NaCl}, 3 \mathrm{~g} \mathrm{CuSO}_{4} 5 \mathrm{H}_{2} \mathrm{O}, 4 \mathrm{~g} \mathrm{ZnSO}_{4} 7 \mathrm{H}_{2} \mathrm{O}, 20 \mathrm{mg} \mathrm{CoSO} 4$ $7 \mathrm{H}_{2} \mathrm{O}, 20 \mathrm{~g} \mathrm{FeSO}_{4} 7 \mathrm{H}_{2} \mathrm{O}, 3 \mathrm{~g} \mathrm{MnSO}_{4} \mathrm{H} 2 \mathrm{O}, 215 \mathrm{~g} \mathrm{CaCO}_{3}, 124 \mathrm{~g} \mathrm{MgSO} 47 \mathrm{H}_{2} \mathrm{O}$, and 1 g NaF. VM, vitamin mix. ${ }^{f}$ Amount of vitamin $D_{3}$ per gram of the diet after biochemical analysis of the diet: VD-0, $11.2 \mathrm{IU} / \mathrm{g}$; VD-1 (control), $27.6 \mathrm{IU} / \mathrm{g}$; VD-2, $42 \mathrm{IU} / \mathrm{g} ; \mathrm{VD}-3,120 \mathrm{IU} / \mathrm{g}$. 
Table 2. Oligonucleotide primers used in real time PCR

\begin{tabular}{ccl}
\hline Genes & Accession Number & Forward and Reverse primers \\
\hline Ef1 & AJ866727 & F: GCTTCGAGGAAATCACCAAG \\
& R: CAACCTTCCATCCCTTGAAC \\
BMP4 & FJ567451 & R: GGCTCACATCAAAGCTCTCC \\
& & F: AGGATCATCTCCTCCCTGGT \\
VDR $\alpha$ & CAJ13719 & R: TGTTACTGGGCCTTCACGTA \\
VDR $\beta$ & F: TCAACAACCTGCTGATGATG \\
& & R: GCCAATAACCTTCTGGATGC \\
Osteocalcin & AY663813 & F: ATGGACACGCAGGGAATCATTG \\
& & R: TGAGCCATGTGTGGTTTGGCTT \\
TRPV6 & EU597485 & R: CCGAGCTCTTCCAAGGTGT \\
\hline
\end{tabular}


Table 3. Growth, survival, surface of mineralized bones per larval surface and malformation rates of larvae fed the experimental diets at day 45. Percentage of secreted trypsin and amylase assayed in intestinal segment related to total trypsin or amylase (mU/segment) and ratio of segmental activity of alkaline phosphatase (AP) and aminopeptidase $N(A N)$ in brush border membrane (BBM) (mU/segment) related to segmental activity of a cytosolic enzyme (U/segment), Leucine-Alanine peptidase (LeuAla) at days 25 and 45. I, intestine; P, pancreas. $\mathrm{n}=4$

\section{Dietary groups}

\begin{tabular}{lcccc} 
& VD-0 & VD-1 & VD-2 & VD-3 \\
\hline Mean body weight, mg & $35.3 \pm 7.2^{\mathrm{bc}}$ & $47.0 \pm 4.5^{\mathrm{a}}$ & $42.9 \pm 4.2^{\mathrm{ab}}$ & $39.5 \pm 5.5^{\text {abc }}$ \\
Survival rate, \% & $52.2 \pm 7.5^{\mathrm{a}}$ & $63.4 \pm 7.2^{\mathrm{a}}$ & $56.7 \pm 18^{\mathrm{a}}$ & $46.7 \pm 11.1^{\mathrm{a}}$ \\
Ossification level/larval surface & $0.9 \pm 0.05^{\mathrm{b}}$ & $3.0 \pm 0.2^{\mathrm{a}}$ & $3.1 \pm 0.6^{\mathrm{a}}$ & $2.2 \pm 0.2^{\mathrm{a}}$ \\
Enzymatic assays & & & \\
$\quad$ & & & \\
$\quad$ Trypsin, \% [I/(P+I)] & & & \\
$\quad$ Day 25 & $28.8 \pm 1.2^{\mathrm{c}}$ & $52.2 \pm 2.9^{\mathrm{a}}$ & $42.7 \pm 4.3^{\mathrm{b}}$ & $42.8 \pm 0.9^{\mathrm{b}}$ \\
$\quad$ & $73.5 \pm 3.0^{\mathrm{a}}$ & $73.2 \pm 1.9^{\mathrm{a}}$ & $68.1 \pm 1.6^{\mathrm{a}}$ & $65.5 \pm 3.9^{\mathrm{a}}$
\end{tabular}

Amylase, \% [I/(P+I)]

\begin{tabular}{|c|c|c|c|c|}
\hline Day 25 & $66.2 \pm 2.2^{\mathrm{c}}$ & $85.3 \pm 2.7^{\mathrm{a}}$ & $79.8 \pm 1.9^{\mathrm{ab}}$ & $76.1 \pm 2.9^{b}$ \\
\hline Day 45 & $66.3 \pm 2.8^{\mathrm{a}}$ & $85.3 \pm 4.2^{\mathrm{a}}$ & $92.6 \pm 2.4^{\mathrm{a}}$ & $84.2 \pm 2.2^{\mathrm{a}}$ \\
\hline
\end{tabular}

AP bbm/LeuAla (X10)

\begin{tabular}{|c|c|c|c|c|}
\hline Day 25 & $0.6 \pm 0.1^{b}$ & $1.6 \pm 0.1^{\mathrm{a}}$ & $0.8 \pm 0.07^{\mathrm{b}}$ & $0.8 \pm 0.04^{b}$ \\
\hline Day 45 & $2.1 \pm 0.3^{\mathrm{a}}$ & $3.0 \pm 0.8^{\mathrm{a}}$ & $3.7 \pm 0.2^{\mathrm{a}}$ & $3.5 \pm 0.2^{\mathrm{a}}$ \\
\hline
\end{tabular}

AN bbm/LeuAla (X100)
Day 25
$0.7 \pm 0.1^{\mathrm{b}}$
$2.4 \pm 0.4^{\mathrm{a}}$
$1.2 \pm 0.2^{\mathrm{b}}$
$0.9 \pm 0.0^{\mathrm{b}}$
Day 45
$2.5 \pm 0.4^{\mathrm{a}}$
$3.9 \pm 1.1^{\mathrm{a}}$
$4.3 \pm 0.6^{\mathrm{a}}$
$3.9 \pm 0.4^{\mathrm{a}}$

Values are expressed as means \pm SD. ${ }^{\mathrm{a}, \mathrm{b}, \mathrm{c},}$ Different superscript letter in the same row are significantly different $(P<0.05)$. 